\title{
A geometria dinâmica do círculo de Apolônio
}

The dynamic geometry of Apollonius circle

\author{
Reynaldo Lopes de Oliveira Jr.* \\ Escola SESC de Ensino Médio, Rio de Janeiro, RJ, Brasil.
}

Recebido em 22 de Fevereiro, 2016. Revisado em 21 de Junho, 2016. Aceito em 30 de Junho, 2016

Neste trabalho, apresento uma nova questão referente à aplicação do círculo de Apolônio no contexto do design de games. Ao invés de determinarmos o ponto de encontro a partir das condições iniciais; na nova questão proposta decidiremos previamente o ponto de encontro/interceptação e calcularemos o instante em que o torpedo deve ser lançado. Na questão proposta em [1] o torpedo e o navio partem ao mesmo tempo (em trajetória retilínea) rumo a interceptação. E se esperarmos um certo tempo $t$ para lançarmos o torpedo? Ou então, e se apontarmos o torpedo para uma determinada posição e desejarmos saber em que instante o navio será interceptado nesta posição? Estas são as novas questões trazidas nesta nota..

Palavras-chave: problemas de perseguição, simulação computacional, simulação com software educacional.

In this paper, I present a new application of the Apollonius circle in a game design context. Instead of determining the meeting point from the initial conditions, in the present proposal a previously prescribed interception point is given and I calculate the instant of time that the torpedo must be launched. In the problem proposed in reference [1] the torpedo and the ship start at the same time (on a straight path) towards the point of interception. Now I pose the following question: What happens if we wait a certain time $t$ to launch the torpedo? What happens if we aim the torpedo to a certain point and we want to know the instant the ship is hit when passing through this point? These are the new questions addressed to in this note.

Keywords: pursuit problems; computational simulation; educational software.

No trabalho [1] foi apresentado, como uma aplicação do círculo de Apolônio, a solução para a interceptação entre dois objetos a uma velocidade constante (um torpedo e um navio porta-aviões).

$\mathrm{Na}$ figura 1 o navio $(\mathrm{N})$ está na posição $(0,0) \mathrm{em}$ $t=0$ de um plano cartesiano.O eixo $\mathrm{x}$ a partir da origem, cruza a posição do torpedo $(\mathrm{T})$. A reta $\mathrm{NAB}$ é a suposta direção a ser seguida pelo navio. Os pontos $\mathrm{A}$ e $\mathrm{B}$ são os pontos onde $\mathrm{N}$ intercepta o círculo de Apolônio.Se o navio e o torpedo partirem ao mesmo tempo de suas posições iniciais, eles se interceptarão em A ou B para um dado $k=\frac{V_{N}}{V_{T}}$. Onde $V_{N}$ é a velocidade escalar do navio e $V_{T}$ é a velocidade escalar do torpedo. Para mais detalhes sobre este problema ver ref. 1].

Neste artigo apresento uma nova questão: e se re-

*Endereço de correspondência: rlojunior@gmail.com solvermos esperar um pouco para atirarmos o torpedo, quais seriam as novas possibilidades de inter-

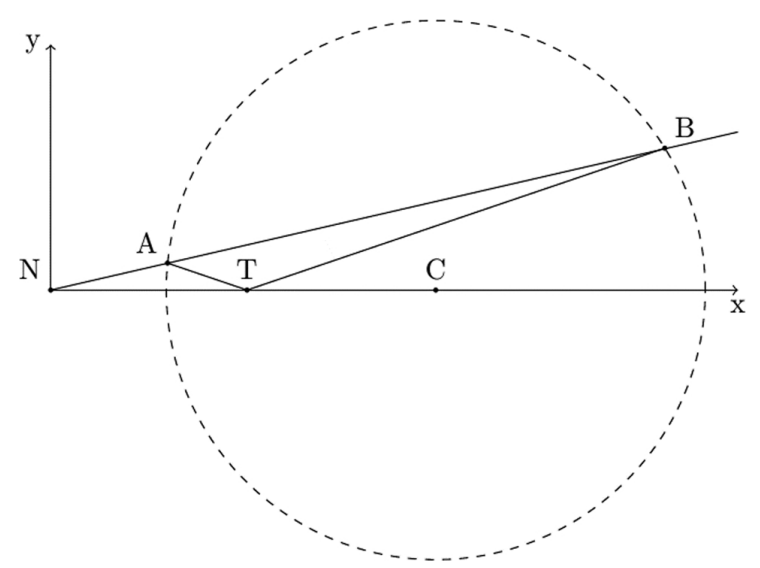

Figura 1: Círculo de Apolônio Estático para $\mathrm{k}=0.7$ 
ceptação? O navio ainda parte da origem do plano cartesiano xy (figura 1) e o torpedo ainda está em T. A nova situação se dá pelo fato do torpedo não partir ao mesmo tempo que o navio.

Considere o navio na origem do plano xy e o torpedo sobre o eixo x na posição T (figura 1). Para este caso o círculo de Apolônio é dado pela equação [1:

$$
\left(x-x_{0}\right)^{2}+\left(y-y_{0}\right)^{2}=R^{2}
$$

onde:

$$
x_{0}=\frac{-x_{T}}{k^{2}-1}, \quad y_{0}=0
$$

e

$$
R=\frac{k x_{T}}{\left|1-k^{2}\right|}, \quad k \neq 1
$$

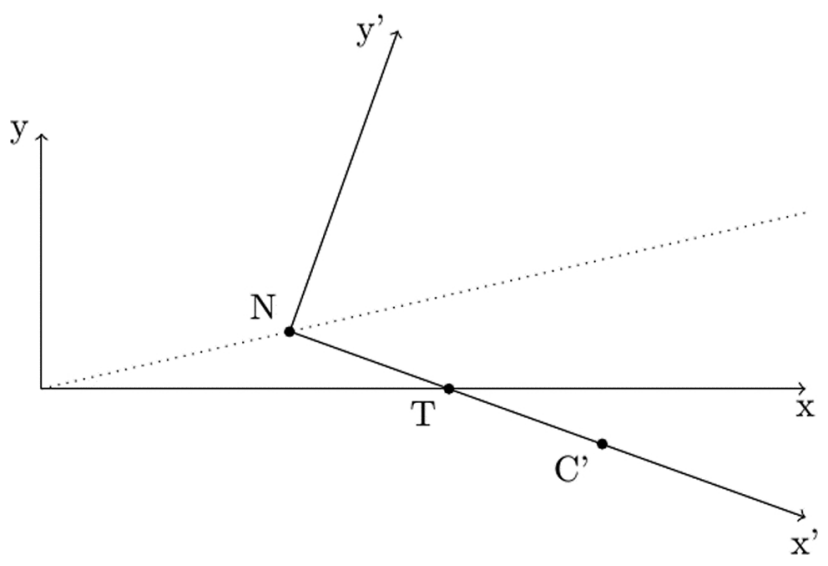

Figura 2: Eixo cartesiano $x^{\prime} y^{\prime}$

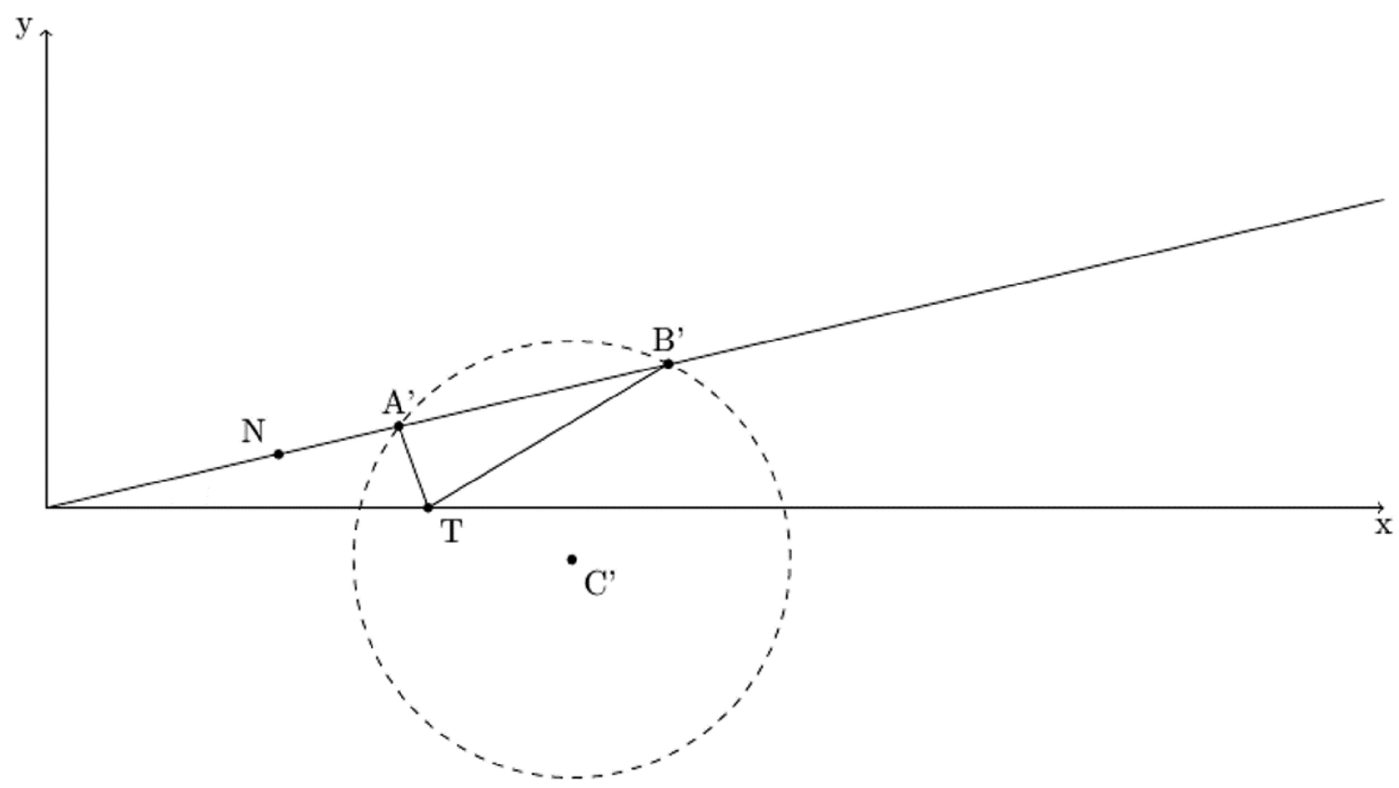

Figura 3: Círculo de Apolônio para $k<1$ em um instante $t>0$.
Imaginemos agora que o navio continue a navegar e o torpedo ainda não tenha sido lançado. Precisamos saber como determinar a cada instante as novas possibilidades de interceptação. Dada a posição de $\mathrm{N}$ em $t>0$, para mantermos a mesma solução que a apresentada em (1) devemos traçar um novo plano cartesiano x'y'. Para a construção deste plano x'y' rotacionamos e transladamos o eixo xy (Figura 2). Observamos assim que o centro do círculo de Apolônio também será rotacionado e transladado. $\mathrm{O}$ novo centro do círculo de Apolônio em $t>0$ será C'. Sendo assim as possibilidades de interceptação entre $\mathrm{N}$ e T serão nos pontos A' e B' conforme mostrado na figura 3. Observe ainda nesta figura que o ponto $\mathrm{N}$, que indica a posição do navio já está em um pouco mais a frente do que quando $t=0$. 


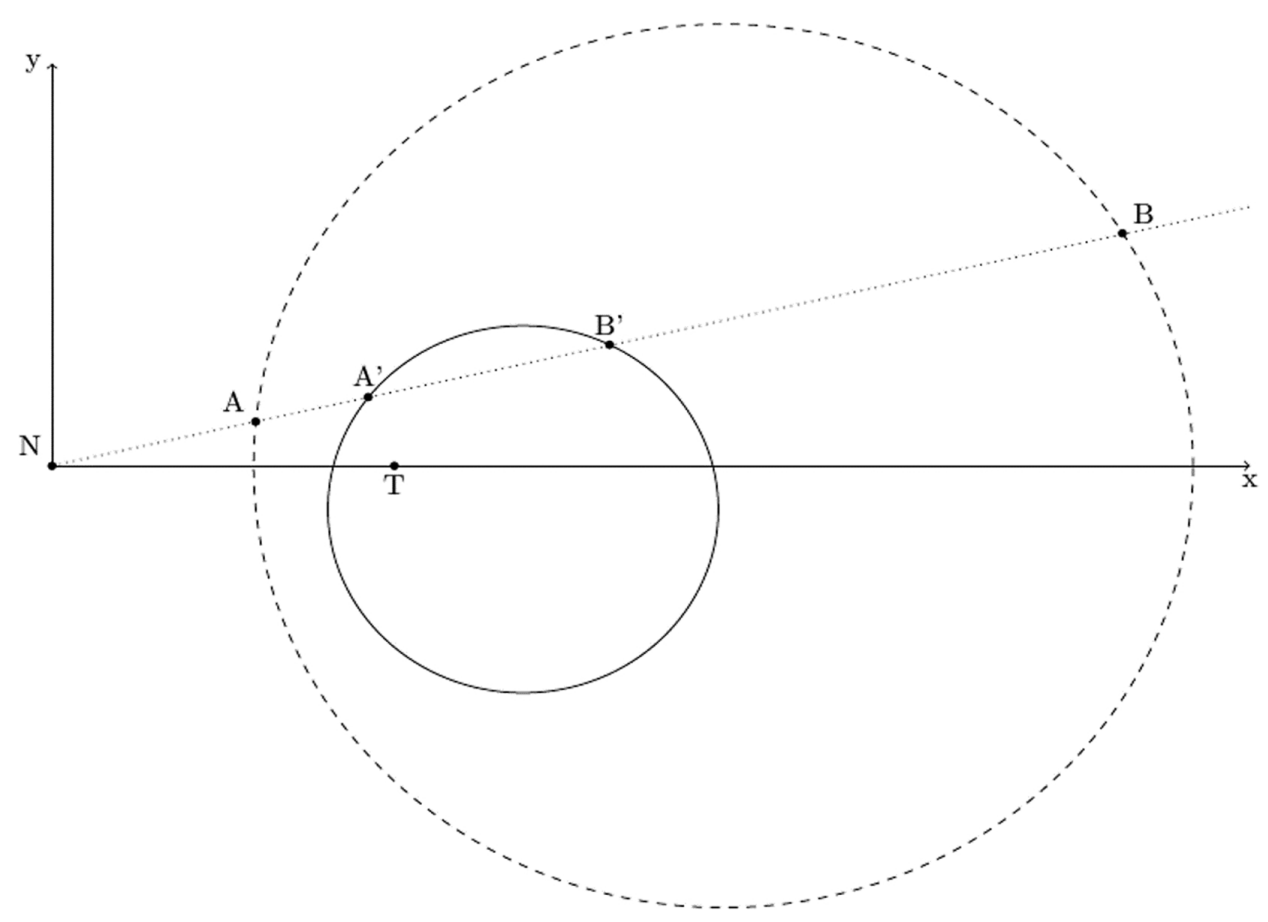

Figura 4: Em linhas tracejadas temos o círculo de Apolônio em $t=0$ conforme mostrado na figura 1 e em linha sólida temos o círculo depois de um tempo $t>0$ conforme mostrado na figura 3

Nesta figura o raio do círculo de Apolônio é menor do que a solução em $t=0$. O raio da circunferência de acordo com (3) depende da posição de T. Como na figura 3 a posição, no novo sistema x'y', muda a cada instante o raio também mudará. Na figura 4 podemos observar a evolução temporal da circunferência.

Sendo assim, se o torpedo demorar um tempo $t>0$ para ser atirado, a nova possibilidade de interceptação será em B' ou em A'.

Com o avanço de softwares matemáticos podemos observar que antes problemas estáticos e imóveis, agora podem ser animados tornando o aprendizado da matemática mais significativo e interessante. Não são poucos os problemas onde nossos alunos têm que "imaginar"rotações, translações das figuras geométricas estáticas do quadro negro. Assim, utilizei o software Geogebra para tornar o problema do círculo de Apolônio, um applet interativo. O link da aplicação especialmente criada para este trabalho está neste endereç ${ }^{1}$. Para acessar a aplicação não é necessário ter o software Geogebra instalado.

A fim de complementar os estudos realizados sobre o círculo de Apolônio, já apresentado nesta revista [1], apresentei a solução de mais uma questão que emergiu a respeito do tema. A nova questão surge

\footnotetext{
$\overline{{ }^{1} \text { http://ggbtu.be/m1325441 }}$
}

a partir da implementação do círculo de Apolônio como algorítimo na programação de jogos de tiro. O jogo a ser desenvolvido é uma releitura do jogo lançado pela Atari em 1977, o Air-Sea Battle [2]. Neste jogo o jogador controla um canhão anti aéreo e deve atingir aviões que passam por cima da cidade. Ambos míssil e avião viajam em trajetórias retilíneas. Sabendo a velocidade do míssil e do avião (ou pelo menos sabendo a razão entre as velocidades) surge a pergunta: quanto tempo devemos esperar para que o míssil intercepte o avião?

O interessante é notar que desta vez, diferente da proposição feita em 11 desejamos previamente definir a posição de interceptação. Refazendo a pergunta em termos matemáticos seria: Em que instante as trajetórias do míssil e do avião interceptarão o círculo de Apolônio? Para resolver esta questão se fez necessário entender como o círculo de Apolônio (e as condições de interceptação) evoluem com o tempo.

\section{Referências}

[1] R. Lopes e A.C. Tort, Revista Brasileira de Ensino de Física 36, 3502 (2014).

[2] Air-Sea Battle, disponível em https: //en.wikipedia.org/wiki/Air-Sea_Battle 